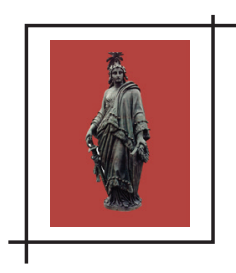

\title{
O DEBATE ENTRE LUTERO E ERASMO: A QUESTÃO DO LIVRE E DO SERVO-ARBITRIO
}

\author{
Gerson Leite de Moraes ${ }^{1}$
}

Resumo: 0 texto em questão recupera um dos grandes capítulos da primeira fase da Reforma Protestante do século XVI. 0 debate entre Lutero e Erasmo sobre a temática da vontade é, sem dúvida, algo digno de ser apreciado e analisado, não somente pelos aspectos teológicos e filosóficos envolvidos na questão, mas, sobretudo, pela capacidade intelectual demonstrada pelos contendores na construção de suas teses. 0 leitor terá a oportunidade de verificar, através do recorte histórico e literário, o ambiente conflagrado do início do século XVI, onde aspectos religiosos misturavam-se o tempo todo com questões de ordem política, tudo isso vivenciado no mais profundo espírito do Renascimento Cultural do início da Modernidade. Nenhuma doutrina religiosa está imune aos interesses e jogos de força do tempo, sendo assim, percebe-se que o debate em questão também é uma ressignificação da temática sobre o livre-arbítrio que vinha desafiando a cristandade ao longo dos séculos, pelo menos desde o final da Antiguidade. Lutero e Erasmo atualizam o debate escrevendo mais um capítulo das controvérsias teológicas e filosóficas que envolvem o tema em questão.

Palavras-chave: Livre-arbitrio. Servo-arbitrio. Modernidade. Teologia. Filosofia.

Lucien Febvre (1878-1956), fundador da Escola dos Annales, especialista em século XVI e que o via como uma "pátria" do espírito, talvez por ser ele mesmo um fervoroso humanista, teve necessariamente que conhecer a fundo os dois personagens do debate em epígrafe. Sobre eles, Febvre tinha visões opostas, enquanto pintava Erasmo como prudente e calculista, agindo sempre em benefício próprio, Lutero é apresentado como fogoso, impulsivo, aquele tipo de sujeito que nunca calcula as consequências de suas palavras e atos. Contudo, não pense o leitor que isso é algo de ruim para Febvre, muito pelo contrário, pois o reformador tem um destaque especial na obra do historiador. Talvez a citação a seguir possa ajudar na compreensão dos nossos personagens debatedores:

1 - Doutor em Ciências da Religião pela PUC-SP e em Filosofia pela Unicamp. É professor do Programa de Pós-Graduação em Ciências da Religião da Universidade Presbiteriana Mackenzie.E-mail: gerson.moraes@mackenzie.br 
Um lógico que defendesse com clareza um sistema de ideias coerentes, perfeitamente ligadas, que não deixassem lugar para o equívoco, não teria sido mais que uma voz no clamor inútil e confuso das Alemanhas. Um homem de bom senso, prudente, e que pesasse suas ações antes de realizá-las, que só pusesse o pé sobre terreno firme e anteriormente sondado, só teria feito e dito o que precisamente fazia e dizia Erasmo. Lutero era mais um homem piedoso que um lógico ou um sábio; um homem piedoso que tratasse de realizar grandes e belas obras, de levar uma vida devota, virtuosa e santa. Era um instrumento que seguia seu impulso sem se preocupar com as dificuldades, com as oposições ou com as contradições que não percebia com a inteligência, mas que conciliava na unidade profunda de um sentimento vivo e dominador. Lutero não é nem um doutor, nem um teólogo: é um profeta (FEBVRE, 1978, p. 95).

Martinho Lutero, sem dúvida, foi um profeta para o seu tempo, mas também foi um erudito teólogo. Escreveu e debateu com figuras ilustres do Renascimento e da Reforma. Ele foi fruto do humanismo renascentista e reconhecia isso de bom grado a partir de uma intervenção de Deus na história dos homens.

A gratidão de Lutero pelos estudos humanistas como auxiliares de uma compreensão linguística da Bíblia era tal que adotou uma visão providencialista deste aspecto do renascimento do conhecimento. "Anteriormente", escreveu, referindo-se ao século anterior, ninguém sabia por que razão Deus provocara o renascimento das línguas (o latim, o hebraico, o grego), mas agora pela primeira vez vemos que tal aconteceu devido ao Evangelho [...] Para este fim, deu a Grécia aos Turcos para que os Gregos, expulsos e dispersos, pudessem disseminar a sua língua e fornecer um incentivo ao estudo de outras línguas também (HALE, 2000, p. 189-190).

Entre 1525 e 1539, envolveu-se em grandes controvérsias com algumas figuras proeminentes, tanto do Renascimento quanto da Reforma. Não adiantava a Igreja Católica pensar em queimar Lutero como um herege, como havia feito com tantos outros, porque, ao contrário destes, Lutero aproveitou como ninguém o avanço da imprensa na época. Todas as controvérsias de Lutero, de uma forma ou de outra, acabavam sendo publicadas, portanto, sua morte não teria condições de impedir o avanço de suas ideias. Como bem lembrou Peter Burke, "a impressão gráfica converteu a Reforma numa revolução permanente" (2006, p. 83).

Lutero envolveu-se num debate instigante com Erasmo de Rotterdam sobre a questão do livre-arbítrio, com Ulrico Zwinglio, líder da igreja suiça de fala alemã sobre questões relativas à Santa Ceia, e com um jovem discípulo seu, nascido na mesma Eisleben, cidade natal de Lutero, chamado João Agrícola. Erasmo era, na década de 20 do século XVI, o mais famoso sábio europeu e vinha sendo cobrado por diversos humanistas sobre seu posicionamento em 
relação à Reforma Religiosa que estava em andamento. Erasmo bem que tentou se furtar dessa responsabilidade, uma vez que o clima em toda a Europa era bastante pesado naqueles dias. Ele foi acusado de ter escrito uma sátira intitulada: As lamentações de Pedro, que, na realidade era uma tentativa de desviar a atenção que estava voltada para ele, exigindo um posicionamento.

Na verdade, eram lamentações de todos os autores do Novo Testamento porque os seus livros já não eram lidos. Paulo sugeria que as obras de João tinham mais saída do que as outras porque as suas ideias eram as de Platão. "Que disparate", retorquia Pedro. "Sabeis que Zebedeu ensinava Platão ao filho?" Tiago atribuia a culpa da negligência aos frades a quem Lucas tinha dado uma vantagem ao escrever "abençoados os mendigos". "Eu não escrevi nada disso", dizia irritado Lucas. Eu disse "abençoados os pobres", referindo-se aos pobres de espírito. Agostinho e Jerônimo juntam-se depois ao grupo. Agostinho diz que há um bom monge entre os agostinhos. Chama-se Martinho Lutero. Agostinho e Jerônimo fazem-Ihe uma visita. Lutero pergunta a Agostinho qual é a melhor ordem monástica. "Os irmãos da Vida Comum", respondeu ele. "Não é a tua, dos agostinhos? Vestem melhor". A isto Agostinho respondeu que o hábito é um assunto sem importância. Jerônimo exorta Lutero a atacar os sofistas. Lutero escusa-se porque teme o papa. "Quem é o papa?" pergunta Jerônimo. "Nunca ouvi falar dele". "É Leão", diz Lutero. "Ah sim!", replica Jerônimo, "Afinal conheço-o. Ele não te vai fazer mal" (BAITON, 1969, p. 207)

Percebe-se na leitura dessa sátira um tom jocoso e erudito, mas que tenta de alguma maneira apaziguar as tensões existentes após o início da Reforma. 0 clima político europeu não era dos melhores naquele tempo. A Europa não estava apaziguada, as guerras eram constantes, e a Reforma era mais um elemento que estava favorecendo esse clima bélico. Reis e nobres estavam se posicionando, ou do lado de Roma, ou do lado dos Reformadores. Henrique VIII, antes de romper com a Igreja Católica e criar a Igreja Anglicana, recebeu o título de "defensor da fé" em razão de sua fidelidade ao papa e porque teceu severas críticas a Martinho Lutero. Ele mantinha correspondências com Erasmo, pressionado a escrever contra alguns posicionamentos teológicos de Lutero (e o tema escolhido foi o livre-arbítrio) exatamente pelo erudito rei da Inglaterra. Erasmo, antes de publicar o seu tratado, que levou o título de De libero arbitrio diatribh sive collatio, enviou um esboço desse escrito ao rei da Inglaterra. No dia $1^{\circ}$ de setembro de 1524, a obra veio a público.

Seu conteúdo parte de uma das mais complicadas temáticas biblicas, voltando-se contra a afirmação feita por Lutero em sua Assertio omnium articulorum. Trata-se de discussão aberta de argumentos, entre os quais também foram colocadas as argumentações de Melanchthon e de Karlstadt. 0 estilo é elegante. Na introdução, alega que o debate é necessá- 
rio, pois Lutero não só discute com os pais da Igreja, mas também com todas as universidades, concílios e decretos papais. Aqui já se evidencia que, ao lado do debate, Erasmo coloca a questão do compromisso em relação à tradição eclesiástica. Erasmo entra, assim, no debate de questões dogmáticas, frente às quais era cético, quando não estavam fundamentadas pela autoridade da Bíblia ou da Igreja. Nesse caso, submetia-se a elas sem qualquer discussão. Teme qualquer fanatismo que possa surgir em decorrência de discussões. Como os pais da Igreja divergem na questão do livre-arbitrio, faz a constatação bastante vaga de que "há algum poder do livre-arbitrio" [...]. Na segunda parte da introdução, dedica-se a questões de método. Fundamental é a questão: Qual o critério da verdade? Lutero reconhece apenas a autoridade da Bíblia. Erasmo aponta, além dela, para a autoridade da tradição interpretativa da Igreja, encontrada em santos, mártires e concilios. Estes defenderam a liberdade da vontade humana. Os santos pais agiram inspirados pelo Espírito Santo. Nessa condição são intérpretes das passagens obscuras da Escritura. Aqui, biblicismo e tradicionalismo se confrontam (DREHER, 1993, p. 13-14).

De servo arbitrio, de Lutero, foi publicado somente em 31 de dezembro de 1525. Sem dúvida, tratava-se de um duelo de titãs. Alguém já disse certa vez, e isso foi propagado de tantas formas que é impossivel saber quem é o autor, mas o primeiro leitor que fez esta observação foi extremamente feliz, em vez de intitular os escritos dos contendores como Do livre-arbitrio e De servo arbitrio, os dois antagonistas poderiam mudar os títulos para Da religião natural e Da religião sobrenatural.

Apesar de citar filósofos em sua obra, ora valorizando-os e na maioria das vezes criticando-os, como na passagem que se segue: "Satanás tornou desprezível a Santa Escritura, para pôr no governo da Igreja suas pestes extraídas da filosofia" (LUTERO, 1993, p. 24), Lutero constrói sua argumentação como teólogo. Em sua obra, intitulada De servo arbitrio, geralmente quando aparece o termo sofista, ou sofistas, no plural, Lutero está fazendo referência aos teólogos escolásticos em geral. Lutero promove diversos ataques à filosofia e faz questão de trazer o debate para o terreno teológico, e procura rebater Erasmo a partir da exegese bíblica:

Tendo em vista que a Escritura anuncia a Cristo em toda parte (como já disse) por meio de comparações e antíteses, de modo que tudo que não tiver o Espírito de Cristo submete a Satanás, à impiedade, ao erro, às trevas, ao pecado, à morte, à ira de Deus, todos os testemunhos que falam de Cristo combaterão o livre-arbítrio. E esses são incontáveis, ou melhor, toda a Escritura. Por isso, se tratarmos deste assunto perante o tribunal da Escritura, serei vencedor em toda linha, de sorte que não sobrará um único jota ou til que não condene o dogma do livre-arbitrio (LUTERO, 1993, p. 210). 
Vale lembrar que a Igreja medieval, sobretudo após o florescimento do Escolasticismo, afirmava que o fiel ao praticar o bem num estado de graça contribuia para a sua salvação. Para Lutero, a tão propalada conciliação entre razão e fé era um absurdo escolástico, pois, para o reformador, a razão não tinha nada em comum com o domínio da fé. Em suma, pode-se dizer que ele via na teologia escolástica um pelagianismo repaginado. Apesar também de afirmar que não aceitaria e nem se sujeitaria à autoridade de outro escritor, Lutero diz claramente quais são as bases que se apoia. "De meu lado, porém, estão Wyclif e Lorenzo Valla, embora também Agostinho, a quem preteres" (LUTERO, 1993, p. 53). Principalmente ao citar Lorenzo Valla, Martinho tinha em mente buscar para si uma linhagem que o colocava numa situação privilegiada no que tange ao método filológico, que, como vimos, era o mais inovador que havia naqueles dias. Contudo, Erasmo também se considerava um herdeiro da tradição de Lorenzo Valla.

Em 15 de maio de 1489, 32 anos após a morte do mestre do humanismo crítico, Erasmo escreveu a Corneille Girard: "pelas regras de elegância e de estilo [o Valla da Elegantiae], eu não confio em ninguém como confio em Lorenzo Valla; não temos ninguém que possa ser comparado a ele, na fineza de espírito e na fidelidade da memória". Em uma outra carta a Corneille Girard, Erasmo diz: "no centro de um hino ao humanismo, Lorenzo Valla retorna insistentemente". Aliás, Valla é centro de uma falsa querela que surgiu entre esses dois amigos (CHAUNU, 1975, p. 308-309).

De John Wyclif (1320-1384) veio a luta contra as pretensões temporais da Igreja e a defesa do confisco de seus bens; de Valla vem a tradição exegética, o gosto pelas palavras, a análise gramatical e o apreço pela boa hermenêutica; já de Agostinho veio toda uma tradição de compreender o homem como um ser totalmente afastado de Deus, decaido e dependente da graça divina. É justamente para esse homem fraco e manchado pelo pecado que Cristo morreu: "nada é mais apto para compreender as palavras de Deus do que a fraqueza de engenho. Foi justamente por causa dos fracos e para os fracos que Cristo veio e enviou sua palavra" (LUTERO, 1993, p. 72).

0 método desenvolvido por Lutero é baseado no pressuposto de que a Bíblia é a palavra de Deus entre os homens e que, ao tomarem-na nesta condição, o Espírito Santo auxilia na leitura e na compreensão da mensagem bíblica: "Para Lutero, a coisa mais importante era Deus ser Deus, para Erasmo era Deus ser bom. Erasmo acreditava na educação; Lutero, na revelação" (RABIL JR., 1991, p. 253-254). 0 próprio Lutero passa por uma experiência carismática com a leitura de Romanos 1.172: "visto que a justiça de Deus se revela no evangelho, de fé em fé, como está escrito: 0 justo viverá por fé". Portanto, Lutero adota um método

2 - A Epistola aos Romanos foi o livro-texto da Teologia Reformada, a Constituição da Reforma. É admitido geralmente por todos os estudiosos que, de todos os comentários clássicos sobre a Epistola, os de Lutero ainda não foram superados (ATKINSON, 1987, p. 118). 
diferente de Erasmo ao analisar a questão do livre-arbitrio, e isso é fundamental para se compreender o debate entre eles. Lutero teve um princípio de organização próprio: partia de um ponto central totalmente não escolástico, não obstante ter desenvolvido uma teologia sistemática. Erasmo não conhecia esse ponto central. Para ele, a Escritura era um mosaico elaborado e misterioso que, quando examinado com a pureza de espírito, à luz do entendimento comum e lavado com os solventes da erudição, revelava ao olho interior do crente a própria face de Cristo. (McCONICA, 1993, p. 88).

0 assunto em discussão é matéria antiga de disputa no campo teológico. Lutero e Erasmo reeditam na Modernidade o velho debate entre Agostinho e Pelágio.

Ademais, é uma doutrina cristã original dos evangelhos, defendida por Agostinho, em acordo com os mestres da Igreja, contra as rasteirices dos pelagianos e cuja purificação de erros e restabelecimento foi o objetivo principal de Lutero, como este o declara expressamente em seu livro De servo arbitrio, a de que a Vontade não é livre, mas está originariamente propensa ao que é mau. Por isso suas obras são sempre pecaminosas e imperfeitas e jamais podem satisfazer à justiça. Esta, entretanto, não nasce de resolução ou pretenso livre-arbítrio e sim pelo efeito da graça, sem participação nossa, como algo que chega de fora para nós. Não somente os dogmas antes mencionados, mas também este último dogma genuinamente evangélico se encontra entre aqueles que nos dias de hoje uma opinião tosca e raquitica rejeita como absurdo ou desfigura. Em realidade, a despeito de Agostinho e Lutero, essa opinião se adequa ao senso comum do pelagianismo, que em verdade é o racionalismo dos dias atuais (SCHOPENHAUER, 2005, p. 512-513).

0 próprio título do escrito de Lutero De servo arbitrio é tomado de Agostinho e procura ser uma resposta a Erasmo. "Daí que, em seu livro $2[8,23]$ Contra Juliano, Agostinho chama o arbitrio antes de servo do que livre" (LUTER0, 1993, p. 78). Erasmo havia definido o livre-arbítrio como a "força da vontade humana pela qual o ser humano pode aplicar-se às coisas que levam à salvação eterna ou delas afastar-se" (LUTERO, 1993, p. 74).

Lutero põe-se então a fazer uma exegese da definição dada por Erasmo e constata que por "força da vontade humana", pode-se entender potência, faculdade, habilidade, aptidão de querer e não querer, escolher, aprovar, desprezar, enfim, tudo aquilo que cabe à vontade, e com isso Lutero põe-se a analisar tanto a vontade humana, quanto a vontade divina. "Pois a vontade de Deus é eficaz e não há como impedi-la, visto que é a própria potência natural de Deus; além disso, ela é sábia, de sorte que não se pode enganá-la" (LUTERO, 1993, p. 31).

Enquanto Lutero descreve a vontade de Deus como algo imutável, infalivel e eterna, gasta muitas páginas para descrever a vontade humana como refém do que aconteceu no Éden. A doutrina do pecado original é a base para que Lutero construa, a partir de uma longa tradição, uma visão antropológica bastante pessimista sobre o homem. 
Luther encontra várias explicações, mas todas se voltam, no final, a um fator comum. Dentre as várias causas para esse tipo de consideração das ações justas é a inclinação maligna da vontade humana (liberum arbitrium), que "está necessariamente em pecado" como parte do "velho homem", submetido à sabedoria da carne do mesmo modo que a vida da serpente está em sua cabeça. Por isso, o que quer que parta do homem fora da graça (extra gratiam) não possui capacidade alguma de levá-lo à justiça. Luther não poderia negar que o arbitrio humano é livre, mas é sempre livre (liberum) enquanto voltado ao que está em seu poder e "inferior a ele"; não pode se voltar, porém, ao que está acima de si, uma vez que está cativo (captivum) do pecado e, assim, não pode escolher o bem de acordo com Deus (MASSEI JÚNIOR, 2008, p. 67-68).

No carreadouro do Apóstolo Paulo e de Agostinho, Lutero se insere e reforça que a vontade humana foi completamente afetada pela queda do homem: "Portanto, assim como por um só homem o pecado entrou no mundo, e pelo pecado, a morte, assim também a morte passou a todos os homens porque todos pecaram" (Romanos, 5.12).

\begin{abstract}
Se todos estamos sob o domínio do pecado e da condenação por causa de um único homem, Adão, como poderíamos empreender qualquer coisa que não fosse pecado e condenável? Pois quando diz "todos", não excetua ninguém, nem a força do livre-arbítrio, nem obrador algum, quer esteja obrando quer não, quer esteja se esforçando quer não; necessariamente estará compreendido entre "todos", como qualquer outro. Também nós não pecaríamos nem seríamos condenados por aquele único delito de Adão, se ele não fosse nosso delito. Pois, quem seria condenado por causa do pecado alheio, ainda mais perante Deus? Ele, porém, não se torna nosso imitando ou fazendo-o, visto que este não poderia ser aquele pecado único de Adão, uma vez que fomos nós que o cometemos, e não ele. Ele se torna nosso por nascimento. Sobre isso, no entanto, é preciso debater em outra ocasião. Assim, pois, o pecado original não deixa outra possibilidade ao livre-arbitrio a não ser pecar e ser condenado (LUTERO, 1993, p. 199-200).
\end{abstract}

Na visão paulina, o pecado e a morte entraram no mundo por causa do pecado (erro de alvo) de Adão, e isso afetou não só a vontade humana, mas aquilo que de fato nos torna humanos, a saber, a razão. Em outras palavras, Lutero desconfia da vontade humana e da razão, pois não se pode e nem se deve confiar nessas faculdades atingidas pelo pecado original:
A Diatribe sonha que o ser humano é integro e são, tal como é em suas próprias coisas para a vista humana. Por isso garrula com estas palavras: "Se quiseres, se fizeres, se ouvires" se zomba do ser humano se seu arbitrio não é livre. A Escritura, porém, define que o ser 
humano é corrupto e cativo, e ainda despreza e ignora soberbamente sua corrupção e seu cativeiro (LUTERO, 1993, p. 87).

Entendendo que o ser humano é inclinado ao mal, em função do pecado, a consequência lógica do pensamento de Lutero é colocar este ser humano num estado de total dependência de Deus. Aqueles que dizem que o ser humano é livre para escolher entre o bem e o mal estão equivocados, na perspectiva de Lutero. "O ser humano perdeu a liberdade, é coagido a servir ao pecado e não pode querer algo de bom" (LUTERO, 1993, p. 84).

Nessas condições, o ser humano não pode ser declarado justo diante de Deus; sua justificação não depende de obras, de ritos, de penitências, de jejuns, de preces ou de indulgências, mas unicamente da graça, como favor imerecido de Deus e pela fé em Cristo Jesus. "Porque, como pela desobediência de um só homem muitos se tornaram pecadores, assim também, por meio da obediência de um só, muitos se tornarão justos. Sobreveio a lei para que avultasse a ofensa; mas onde abundou o pecado, superabundou a graça" (Romanos 5.19-20).

Os textos do Apóstolo Paulo são usados em demasia por Lutero. "Por isso meu Paulo permanece firme como devastador invicto do livre-arbítrio" (LUTERO, 1993, p. 197). Em contrapartida, acusa Erasmo de fazer uma péssima exegese dos textos paulinos. "Mas a Diatribe finge não ver todo o corpo do debate paulino e a direção para a qual Paulo tende, consolando-se entrementes com palavras tiradas [do contexto] e distorcidas" (LUTERO, 1993, p. 139).

Se Paulo é a referência bíblica mais usada por Lutero, é natural que venha à tona a questão da Justificação. Quem é Justo diante de Deus? De que maneira processa-se a salvação do cristão? Esse é um ato exclusivo de Deus ou o homem pode contribuir para alcançá-la? Na visão de Lutero, a Escolástica influenciada por Aristóteles errou drasticamente quando acentuou o papel das obras no processo de justificação dos homens. Esse erro continuava nos dias de Lutero:

Os teólogos do tempo de Lutero eram também vítimas deste erro. Influenciados por "Aristóteles em sua Ética", os teólogos escolásticos e contemporâneos de Lutero não entenderam a verdadeira teologia, e vincularam os pecados e a justiça apenas às obras (opera), "em sua execução ou privação, igualmente". Mas acerca deste ponto Lutero escreve a Spalatin, em 9 de outubro de 1516, que "não é como Aristóteles pensa, [...] nos tornamos justos fazendo coisas justas (a não ser por dissimulação)". O Filósofo teria determinado que a justiça é estabelecida, purificada a partir das coisas/atos exteriores (exterioribus actis) praticados frequentemente ao máximo. Luther não aceita que isso se aplique à compreensão teológica da relação do homem com Deus, porque, se o homem está necessariamente em pecado, suas ações também o estão, independentemente da frequência de sua prática (MASSEI JÚNIOR, 2008, p. 68-69). 
Lutero faz ataques veementes à razão em virtude da confiança que o homem nela deposita, na tentativa de tornar-se um ser autônomo. A razão e a vontade humana afetadas no Éden não garantem autonomia ao homem, mas o colocam numa profunda dependência da graça divina:

\begin{abstract}
A vontade humana se acha portanto colocada entre Deus e Satã e se deixa guiar e esporear como um cavalo. Se é Deus a guiá-la, vai aonde Deus quer e como Ele quer, como diz o Salmo LXXIII, v.22: "Eu sou para ti um animal estúpido". Se Satã dela se apossa, vai aonde ele quiser e como quiser. Ora, a vontade humana em tudo isso não é livre de escolher um senhor: os dois cavaleiros combatem e disputam a posse dela (LUTERO, apud DELUMEAU, 1989, p. 107).
\end{abstract}

Na visão de Lutero, se de fato o homem possui livre-arbitrio em matéria de salvação, "que necessidade há ainda de Cristo? Que necessidade do Espírito?" (LUTERO, 1993, p. 103).

Em todo o livro De servo arbitrio, Lutero repetidas vezes exalta as qualidades de Erasmo, mas não compreende como tão douto autor conseguiu escrever tão indouto livro:
Teu livro se me tornou tão sórdido e sem valor, que me compadeci muito de ti pelo fato de poluires tua bela e engenhosa dicção com semelhante sordidez e me indignei com a matéria indigníssima que é veiculada com tão preciosos argumentos de eloquência, como se rebota- Iho e esterco fossem transportados em recipientes de ouro e prata (LUTERO, 1993, p. 17).

Essa disputa entre Erasmo e Lutero reflete duas visões muito diferentes sobre o mesmo tema. Erasmo representa a liberdade, o mérito e a autonomia dos homens:
Quando ouço dizer que o mérito humano é tão nulo que todas as próprias obras das pes- soas de bem são dos pecadores, que a nossa vontade não tem mais poder que a argila entre as mãos do oleiro, que tudo o que fazemos e queremos resulta duma necessidade absoluta, o meu espírito experimenta com isso numerosas inquietações (ERASMO, apud VÉDRINE, 1971, p. 53).

Lutero aponta para o homem sem mérito algum diante de Deus em função do pecado, para o homem que está morto em seus delitos e pecados e carece da ação salvífica de Deus. Enquanto Erasmo é o lídimo representante do humanismo otimista, Lutero é o representante do humanismo pessimista. No final do livro De servo arbitrio Lutero tenta mostrar a grandeza da erudição de Erasmo agradecendo-Ihe a oportunidade de debater com figura tão insigne e o conclama a tentar entender as afirmações feitas no decorrer da obra: 
Agora, meu Erasmo, peço-te, por Cristo, que cumpras o que prometeste; pois prometeste ceder ao que ensina algo melhor. Esquece a consideração de pessoas! Admito que és um grande homem e dotado por Deus com muitos dos mais nobres dons, para não falar dos demais, de teu talento, erudição e da eloquência quase milagrosa. Eu, no entanto, nada tenho e nada sou, a não ser que quase possa gloriar de ser cristão. Além disso, elogio e gabo muito em ti o seguinte: és o único que atacou a questão em si, isto é, a questão essencial, e não me fatigaste com aqueles assuntos secundários sobre papado, o purgatório, as indulgências e outras coisas deste tipo que mais são frivolidades do que questões [sérias], pelas quais até agora quase todos tentaram caçar-me em vão. Tu como único reconheceste o ponto central de toda [controvérsia] e pegaste a coisa pela gravata; por isso te agradeço de coração (LUTERO, 1993, p. 215).

0 fato é que o duelo literário e teológico entre os antagonistas sobre o "arbítrio", fez com que os contemporâneos tivessem que optar. "Revelou-se impossivel, a menos que se traísse um ou outro dos dois inimigos, conciliar a fidelidade a Lutero e a seus ensinamentos com a admiração por Erasmo e sua obra" (FEBVRE, 2012, p. 282). Contudo, por mais incrível que pareça, a Confissão de Augsburgo, elaborada para ser o credo luterano e que teve forte influência de Filipe Melanchton, promove uma certa conciliação entre as duas partes. Heinz Scheible (2013, p. 160-161), escrevendo a biografia de Melanchton, diz que no artigo 18 da Confissão ocorreu a tal conciliação:

Quanto ao livre-arbitrio, ensina-se que o homem tem, até certo ponto, livre-arbitrio para viver exteriormente de maneira honesta e escolher entre aquelas coisas que a razão compreende. Todavia, sem a graça, o auxílio e a ação do Espírito Santo, o homem é incapaz de ser agradável a Deus.

Sem dúvida, o debate entre Lutero e Erasmo foi um dos grandes capítulos iniciais da Reforma Protestante. A doutrina do livre-arbítrio retornará no contexto da Reforma Calvinista e forjou um conceito que tem acompanhado Calvino ao longo do tempo, de forma equivocada e maldosa, na maioria das vezes, que é a doutrina da predestinação, colocada como tema central da teologia calvinista, o que de fato, não é verdade. Mas este já é um outro assunto.

\section{The debate between Lutero and Erasm: the question of the free and the servant will}

Abstract: The text in question retrieves one of the great chapters of the first phase of the Protestant Reformation of the 16th century. The debate between Luther and Erasmus on the theme of the will is undoubtedly something 
to be appreciated and analyzed, not only for the theological and philosophical aspects involved in the issue, but above all, for the intellectual capacity shown by the contenders in the construction of their theses. The reader will have the opportunity to check through the historical and literary perspective, the conflicting environment of the beginning of the 16th century, where religious aspects were constantly mixed with political issues, all of this experienced in the deepest spirit of the Cultural Renaissance of the beginning of Modernity. No religious doctrine is immune to the interests and games of the time force, therefore, it is clear that the debate in question is also a reframing of the theme about free will that has been challenging Christianity throughout the centuries, at least since the end of antiquity. Luther and Erasmus update the debate by writing yet another chapter of the theological and philosophical controversies surrounding the subject in question.

Keywords: Free Will. Servant-Will. Modernity. Theology. Philosophy.

\section{REFERÊNCIAS}

ATKINSON, J. Lutero y el nacimiento del protestantismo. Madrid: Alianza Editorial, 1987.

BAITON, R. H. Erasmo da Cristandade. Lisboa: Fundação Calouste Gulbenkian, 1969.

BURKE, P. Uma história social da mídia: de Gutenberg à internet. Rio de Janeiro: Zahar, 2006.

CHAUNU, P. Le temps des reformes: histoire religieuse et système de civilisation. La crise de la chrétienté - L'éclatement 1250-1550. Paris: Fayard, 1975.

DELUMEAU, J. Nascimento e afirmação da Reforma. São Paulo: Pioneira, 1989.

DREHER, M. N. Da vontade cativa. In: LUTERO, M. Obras selecionadas: debates e controvérsias v. 2. São Leopoldo: Sinodal; Porto Alegre: Concórdia Editora, 1993. 4 v.

FEBVRE, L. Febvre: história. São Paulo: Ática, 1978.

FEBVRE, L. Marinho Lutero, um destino. São Paulo: Três Estrelas, 2012.

FEBVRE, L. O problema da incredulidade no século XVI: a religião de Rabelais. São Paulo: Companhia das Letras, 2009.

HALE, J. A civilização europeia no Renascimento. Lisboa: Editorial Presença, 2000.

LUTERO, M. Obras selecionadas: debates e controvérsias v. 2. São Leopoldo: Sinodal; Porto Alegre: Concórdia Editora, 1993. 4 v.

MASSEI JÚNIOR, W. Os limites da razão em Luther e Schopenhauer. 2008. Dissertação (Mestrado em Filosofia) - Universidade Estadual de Campinas, Campinas, 2008.

McCONICA, J. Renaissance thinkers: Erasmus, Bacon, More, Montaigne. Oxford: Oxford University Press, 1993. 
RABIL JR., A. (ed.). Renaissence humanism: foundations, forms and legacy. Humanism Beyond Italy. Philadelphia: University of Pennsylvania Press, 1991. v. 2.

SCHEIBLE, H. Melanchton, uma biografia. São Leopoldo: Sinodal, 2013.

SCHOPENHAUER, A. O mundo como vontade e como representação. São Paulo: Editora Unesp, 2005.

VÉDRINE, H. As filosofias do renascimento. Mem Martins: Publicações Europa-América, 1971. 